\title{
Tricopter Vehicle Frame Structure Design Integrated as Platform of Fixed Wing Atha Mapper 2150
}

\author{
Kaspul Anuar ${ }^{\text {a,* }}$, Warman Fatra ${ }^{\text {b }}$, and Musthafa Akbar ${ }^{\text {a }}$ \\ a) Mechanical Engineering Department, Universitas Riau, Indonesia \\ *Corresponding author: kaspul.anuar@lecturer.unri.ac.id
}

\section{Paper History}

Received: 14-May-2020

Received in revised form: 28-June-2020

Accepted: 30-July-2020

\begin{abstract}
To upgrade aerial vehicle of Atha Mapper 2150 capable of vertical take-off and landing capability, it needs to be integrated to the tricopter vehicle. In this study the tricopter frame structure was designed based on the Atha Mapper 2150 fixed wing vehicle. This study began with a calculation process to determine the dimensions of the tricopter.. Next, the process of building four tricopter concept designs with variations of the shape of the frame and the cross section of the arm. The four concept designs are selected using a decision matrix. Based on the values in decision matrix table, the design concept I (Y configuration and rectangular arm cross section) was the best design, because it has the highest weighting value. The selected design was then simulated for its structural strength in Ansys software by giving a load of thrust to the three arms of the tricopter frame. In the middle of frame is given a boundary condition in the form of hinges. From the static simulation results of the tricopter frame structure, the maximum stress value was $54,126 \mathrm{MPa}$, which occurred on the M3 arm. The greatest total deformation also occurred in the M3 arm with a value of $10,335 \mathrm{~mm}$. The safety factor value of tricopter frame structure was 8.77. This shows the tricopter frame structure with the main material in the form of carbon fiber, acrylic and PLA meets the required safety criteria.
\end{abstract}

KEY WORDS: Tricopter, Frame, Vehicle, Fix Wing.

\author{
NOMENCLATURE \\ VTOL Vertical Take-Off and Landing \\ MTOW Maximum Take-Off Weight \\ CFRP Carbon Fiber Reinforced Polymer
}

\subsection{INTRODUCTION}

A multicopter is an unmanned flying vehicle shaped like a helicopter with a motor and propeller more than one [1]. The advantages of a multicopter when compared to other flying vehicles are its ability to fly vertically, the ability to remain in the air and the ability to fly in narrow open air spaces. Multicopter can be controlled manually using a radio device or on autopilot using a microcomputer device. Multicopter has been used for civilian purposes with a variety of purposes, such as mapping, monitoring, surveying the area of natural disasters, monitoring the flow of traffic, transporting goods in remote areas and atmospheric research [2]. One type of multicopter that has three motors and three propellers is called a tricopter. The Atha Mapper 2150 is a fixed wing type of flying vehicle that has been successfully designed by the University's research team in Unri. Atha Mapper 2150 has a wingspan of 2,150 mm and a T-Tail shaped tail. As the name implies, Atha Mapper 2150 is used to support the mapping of an area, be it an estate, settlement or industrial forest area [3].

The use of fixed wing type airplanes such as the Atha Mapper 2150 has weaknesses when taking off and landing. Fixed wing type flying vehicles require relatively wide open air space to be safe during takeoff and landing [4]. The development of fixed wing type flight technology lately has led to the type of Vertical Take-Off and Landing (VTOL). The VTOL fixed wing vehicle is a vehicle resulting from the merger of multicopter with fixed wing. The advantage of this vehicle is that it can take off and land vertically, so that the need for open air space for takeoff and landing can be minimized. Then, during a mapping mission, the VTOL fixed wing vehicle will transition from copter mode to plane mode and fly at cruise speed. Generally, the type of multicopter integrated with fixed wing flying rides is a multicopter with type four propellers and four driving motors. The use of a multicopter type four propeller vehicle has a weakness in terms of inefficient electricity consumption, so the flight time of the vehicle will be reduced. So that the Atha Mapper 2150 vehicle has VTOL capability, in the future this vehicle will be integrated with a multicopter type three propeller vehicle (tricopter). The tricopter vehicle has advantages in terms of total mass, volume and energy consumption, which is more efficient [5]. 
In this research the development of the Atha Mapper 2150 vehicle with VTOL capability will begin by designing the tricopter vehicle frame structure. The design process begins by making a selection matrix of several variables to get the best tricopter design. Furthermore, the selected tricopter design will be simulated its structural strength using Ansys software to investigate the stress value, safety factor and deflection of the tricopter frame.

\subsection{METHOD}

\subsection{Vehicle of Atha Mapper 2150 Specification}

In this study, the tricopter frame was designed based on the Atha Mapper 2150 vehicle specifications. The Atha Mapper 2150 specification was needed in the future tricopter frame design, which integrated to the Atha Mapper 2150 vehicle. Table 1 shows the specifications of Atha Mapper 2150 [3].

Based on the Atha Mapper 2150 specifications, the tricopter vehicle was designed to have a lifting capacity of $6 \mathrm{~kg}$. The thrust requirement for a brushless motor on a tricopter was $\geq 2$ $\mathrm{kg}$. The need for lift (thrust) of this motor was adjusted to the specifications of the brushless motor on the market, namely the $340 \mathrm{KV}$ type motor.

Table 1: Specification of Atha Mapper 2150

\begin{tabular}{ll}
\multicolumn{1}{c}{ Parameter } & \multicolumn{1}{c}{ Annotation } \\
\hline Wing span & $2150 \mathrm{~mm}$ \\
\hline Chord & $160 \mathrm{~mm}$ \\
\hline Length of uav & $1680 \mathrm{~mm}$ \\
\hline Distance of brushless motor & $700 \mathrm{~mm}$ \\
\hline Maximum take-off weight & $4.75 \mathrm{~kg}$ \\
\hline Material & $\begin{array}{l}\text { Fiberglass, Carbon fiber and } \\
\text { Hardfoam }\end{array}$ \\
\hline Flight time & 30 minutes \\
\hline Propulsion & Brushless motor 980kv (twin) \\
\hline Battery capacity & $10.800 \mathrm{mAh}$ (4 sell) \\
\hline
\end{tabular}

\subsection{Calculation of Tricopter Frame Dimension}

The dimensions of the tricopter frame are designed based on the distance between the motor axis and the length of the Atha Mapper 2150 vehicle. In addition, the position of the center of gravity between the tricopter frame and the Atha Mapper 2150 must coincide with each other in the $\mathrm{x}$ and $\mathrm{y}$ axes. The determination of the dimensions of the tricopter is also influenced by the size of the propeller used.

After obtaining the dimensions of the tricopter frame, then the process is continued by designing the tricopter frame arm. The tricopter arms are designed based on variations in their profile. Variation of the cross-section profile is made in the form of a square and circle (hollow). Figure 1 displays the profile of the tricopter frame arm to be used.

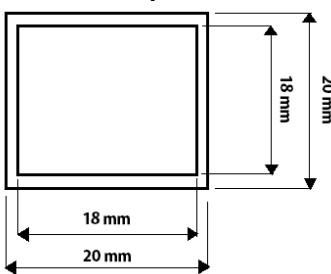

(a)

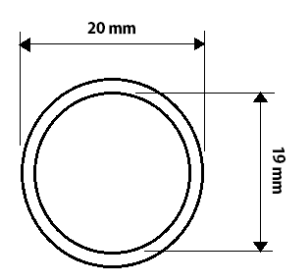

(b)
Figure 1: Profile of tricopter arm cross section (a) square, (b) circle

\subsection{Preliminary Static Simulation and Decision Matrix}

In the field of aeronautics, the use of strong and lightweight materials is very important to consider. Carbon fiber is suitable for applications that meet the requirements of strength, stiffness, lightness and resistance to fatigue. Therefore, in this study the material making up the arms and middle plate on the tricopter frame is determined using carbon fiber material. Alternative tricopter frame designs are made into several concepts. The design concept is varied based on the frame configuration shaped like the letters $\mathrm{Y}$ and $\mathrm{T}$. The tricopter frame concept design.can be seen in Figure 2.

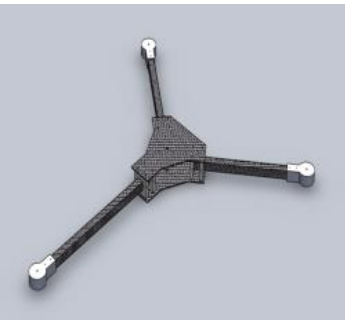

(a)

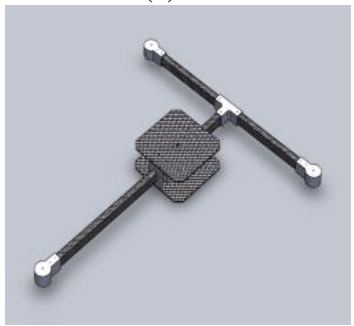

(c)

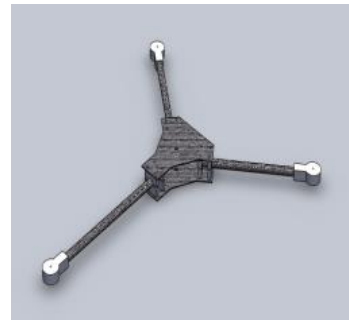

(b)

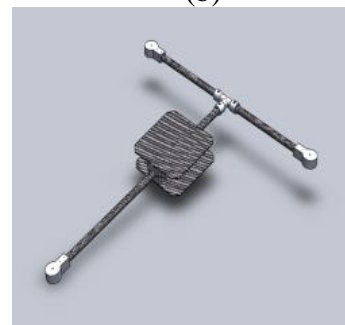

(d)
Figure 2: Design concept of tricopter framework (a) concept 1, (b) concept 2, (c) concept 3, (d) concept 4

The next four tricopter frame design concepts are then carried out initial static simulations using Ansys software. In this initial simulation, the meshing used was of the automatic type. From the results of the static simulation, the decision making matrix is continued. The decision making matrix is a method of making decisions on a number of alternatives which are limited in number. The goal is to get the best tricopter design based on predetermined decision criteria.

\subsection{Calculation of maximum mass (MTOW) of selected tricopter vehicle}

After obtaining the best concept design of the tricopter vehicle, then the MTOW calculation is performed from the tricopter vehicle. This calculation is based on electronic component specification data to be used and geometry data displayed by Ansys software.

\subsection{Static Simulation on Selected Tricopter Frame Design}

At this stage, the size of the meshing element is determined by first doing a static simulation of the quadcopter vehicle from the results of previous studies by varying the size of the meshing element [6]. The size of the meshing element that produces the maximum stress with the smallest percentage of error will be determined as the size of the meshing that will be used in this study.

After obtaining the appropriate meshing size, then a tricopter frame structure simulation is performed. The simulation process begins with engineering data input. Figure 3 shows the engineering data input menu display on Ansys. 


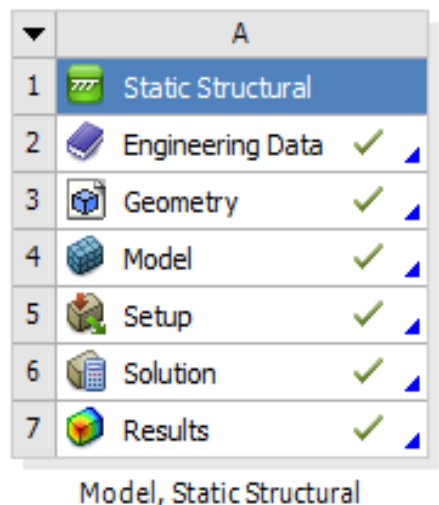

Figure 3: Display engineering data in input menu

Data Engineering Input is the process of entering the mechanical properties of the tricopter frame material. In this study, the properties of the Carbon Fiber Reinforced Polymer (CFRP) material were obtained through tensile testing conducted at the Material Testing Laboratory of the Department of Mechanical Engineering, University of Riau. Tensile testing was carried out using a Universal Testing Machine, with a draw speed of $5 \mathrm{~mm} / \mathrm{min}$ at room temperature with the ASTM D 638 standard [7]. After tensile testing of 4 specimens, yield strength values will be obtained. The modulus of elasticity of the carbon fiber material is obtained using the following equation [8].

$$
\begin{aligned}
& \text { Stretches }(\varepsilon)=\frac{\Delta \mathrm{L}}{\mathrm{Lo}} \\
& \text { Elasticity }(\mathrm{E})=\frac{\sigma}{\varepsilon}
\end{aligned}
$$

After obtaining all the data properties of the carbon fiber material, its was inputting the data properties to the Ansys software in the Data Engineering section. It can be seen in Figure 4 the engineering data menu display on Ansys software. For Acrylic and Polylactic Acid (PLA) material the properties of these two materials are obtained by reference. Furthermore, the file from the three-dimensional image of the tricopter

\begin{tabular}{|c|c|c|c|c|c|c|c|c|c|}
\hline & & & & & & & & & $x$ \\
\hline & A & & B & c & & D & & & \\
\hline 1 & Contents of Engineering Data & $\risingdotseq$ & & :ource & & :scription & & & \\
\hline 2 & I Material & & & & & & & & \\
\hline 3 & Acrylic & & 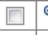 & 窟 & & & & & \\
\hline 4 & $\begin{array}{l}\text { Carbon Fiber Reinforced } \\
\text { Polymer }\end{array}$ & & ( & 䁃 & & & & & \\
\hline 5 & 6 Filament PLA & & 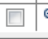 & 罙 & & & & & a \\
\hline Prope & s of Outine Row 4: Carbon Fiber Reinf & arced & Polyme & & & & & & $x$ \\
\hline & $A$ & & & & B & c & & D & E \\
\hline 1 & Property & & & & Value & Unit & & $\otimes$ & [p] \\
\hline 2 & 7 Density & & & & 1.49 & $g \mathrm{~cm}^{\wedge}-3$ & 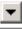 & 回 & 回 \\
\hline 3 & 日田 Isotropic Elasticity & & & & & & & 可 & \\
\hline 4 & Derive from & & & & Young's M... $=$ & & & & \\
\hline 5 & Young's Modulus & & & & 16671 & MPa & - & & \\
\hline 6 & Poisson's Ratio & & & & 0.1 & & & & \\
\hline 7 & Bulk Modulus & & & & $6.9463 E+09$ & $\mathrm{~Pa}$ & & & \\
\hline 8 & Shear Modulus & & & & $7.577 \pi+09$ & $\mathrm{~Pa}$ & & & \\
\hline 9 & $\square \square$ Field Variables & & & & & & & & \\
\hline 10 & Temperature & & & & Yes & & & & \\
\hline 11 & Shear Angle & & & & No & & & & \\
\hline 12 & Degradation Factor & & & & No & & & & \\
\hline 13 & 7 Tensile Yield Strength & & & & 475.13 & $\mathrm{MPa}$ & \pm & 回 & 回 \\
\hline 14 & 7 Tensile Ultimate Strength & & & & 475.13 & $\mathrm{MPa}$ & 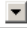 & 回 & 回 \\
\hline
\end{tabular}
vehicle is inputted into the geometry input section.

Figure 4: Display data engineering menu on Ansys software
After the geometry has been inputted, the next step is to make meshing, setup the load and support conditions of the vehicle and finally the solution process is performed. Figure 5 shows the setup of the style and boundary conditions of the tricopter frame in Ansys software.

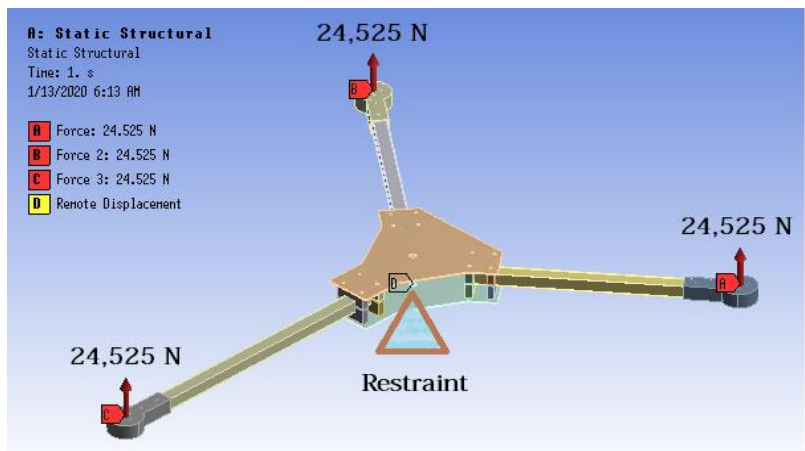

Figure 5. Setup of tricopter style and boundary condition

\subsection{RESULT AND DISCUSSION}

\subsection{Tricopter Order Dimension Calculation Results}

The dimensions of the tricopter frame are designed based on the distance between the motor axes, the length of the vehicle and the position of the Atha Mapper center of gravity 2150 and the size of the propeller used. Figure 6 shows the dimensions of the resulting tricopter frame design.

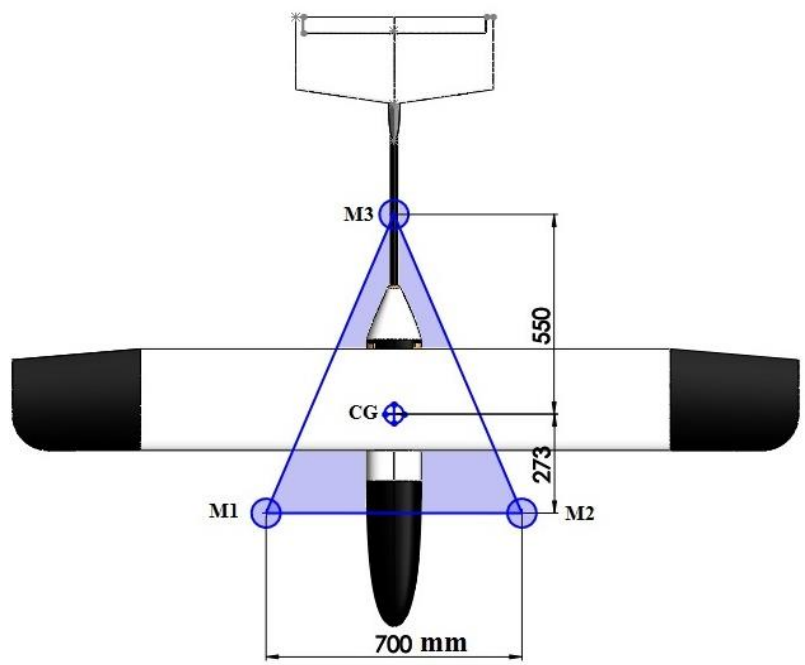

Figure 6: Dimensions of the tricopter frame design

\subsection{Initial Static Simulation Results on Alternative Tricopter Designs}

The whole design concept of the tricopter's frame is simulated in its structural strength. Structural strength simulation is carried out by giving a load of $24,525 \mathrm{~N}$ thrust motor on each arm with fixed support type at the Center of Gravity. The purpose of this simulation is to find out the best design from several design alternatives. The best design criteria are designs that have the smallest maximum stress, the smallest total deformation, the smallest total mass, ease of fabrication, ease of assembly and aesthetics. The following table is shown, Results of static simulations of several design alternatives with the help of Ansys software. 
Table 2: Static simulation results from all tricopter concept designs

\begin{tabular}{lllll}
\hline Parameter & \multicolumn{5}{c}{$\begin{array}{l}\mathbf{1}^{\text {st }} \text { Concept } \\
\text { (Y-Configuration) }\end{array}$} & $\begin{array}{l}\mathbf{2}^{\text {nd }} \text { Concept } \\
\text { (T-Configuration) }\end{array}$ \\
\hline $\begin{array}{l}\text { Cross section } \\
\text { of arm }\end{array}$ & $\begin{array}{l}\text { Square } \\
\text { hollow }\end{array}$ & $\begin{array}{l}\text { Cylindrical } \\
\text { hollow }\end{array}$ & $\begin{array}{l}\text { Square } \\
\text { hollow }\end{array}$ & $\begin{array}{l}\text { Cylindrical } \\
\text { hollow }\end{array}$ \\
\hline $\begin{array}{l}\text { Frame } \\
\text { design }\end{array}$ & & & & \\
\hline Maximum & 24.104 & 40.375 & 24.366 & 35.101 \\
stress & $\mathrm{MPa}$ & $\mathrm{MPa}$ & $\mathrm{Mpa}$ & $\mathrm{MPa}$ \\
\hline Total & 9.298 & 15.557 & 12.331 & 15.961 \\
deformation & $\mathrm{mm}$ & $\mathrm{mm}$ & $\mathrm{mm}$ & $\mathrm{mm}$ \\
\hline \multirow{2}{*}{ Total mass } & 519 & 713 & 639 & 762 \\
& gram & gram & gram & gram \\
\hline
\end{tabular}

Table 3: Matrix of decision making

$$
1^{\text {st }} \text { Concept } \quad 2^{\text {nd }} \text { Concept }
$$

Criterion Score (Y-Configuration) (T-Configuration)

\begin{tabular}{lccccc} 
& $(\%)$ & $\begin{array}{c}\text { Square } \\
\text { hollow }\end{array}$ & $\begin{array}{c}\text { Cylindrical } \\
\text { hollow }\end{array}$ & $\begin{array}{c}\text { Square } \\
\text { hollow }\end{array}$ & $\begin{array}{c}\text { hollow } \\
\text { hollowal }\end{array}$ \\
\hline Strength & 30 & 4 & 3 & 4 & 2 \\
\hline $\begin{array}{l}\text { Mass and } \\
\text { Volume }\end{array}$ & 25 & 4 & 2 & 3 & 2 \\
\hline $\begin{array}{l}\text { Ease of } \\
\text { fabrication }\end{array}$ & 20 & 3 & 4 & 2 & 3 \\
\hline $\begin{array}{l}\text { Ease of } \\
\text { Assembly }\end{array}$ & 15 & 2 & 2 & 3 & 3 \\
\hline Aesthetics & 10 & 3 & 3 & 2 & 2 \\
\hline Total & 100 & 3.4 & 2.8 & 3.0 & 2.35 \\
\hline
\end{tabular}

Information: $1=$ Poor $3=$ Good $2=$ Enough $4=$ Very Good

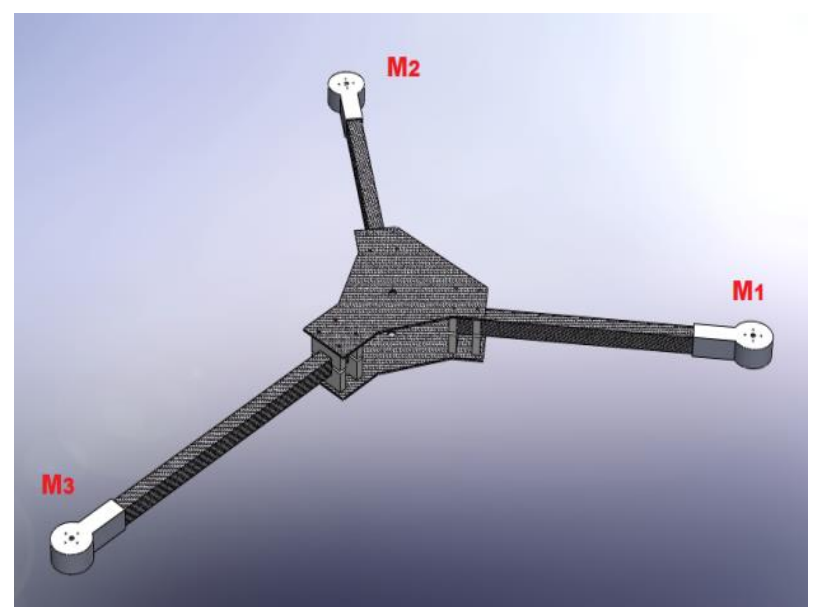

Figure 7: Vehicle of tricopter's selected concept design (Concept I)

The results of this initial simulation are used to determine the best design through the decision making matrix. Table 3 displays the decision making matrix for the tricopter frame design.

Based on table 2, each tricopter frame concept design has a mass of less than $1.25 \mathrm{~kg}$. This shows that every design deserves to be integrated with the Atha Mapper 2150 vehicle.
To choose the best design, selection is done by making a decision making matrix. Based on table 3, it appears that the design concept I is the best design (highest score). In concept I design, the frame configuration has the smallest stress, the smallest deformation and the lightest total mass. Figure 7 shows the design concept of the selected tricopter vehicle (concept I).

\subsection{Mass Calculation Results from the Tricopter Design}

After getting the best design among several concepts, then the final MTOW calculation from the selected tricopter is performed. Table 4 below shows the results of calculating the mass of each component of the selected tricopter.

In Table 4, it is known that the maximum mass (MTOW) of the tricopter vehicle is 5490.3 grams. Thus MTOW tricopter vehicles meet predetermined criteria, which is equal to $\leq 6 \mathrm{~kg}$.

Table 4: Results of MTOW tricopter calculation

\begin{tabular}{lcl}
\hline \multicolumn{1}{c}{ Component } & Mass (gram) & \multicolumn{1}{c}{ Annotation } \\
\hline $\begin{array}{l}\text { Frame of } \\
\text { Tricopter }\end{array}$ & 519.3 & $\begin{array}{l}\text { 3D Design Software } \\
\text { (Solidwork) }\end{array}$ \\
\hline Payload & 4750 & $\begin{array}{l}\text { Spesification of UAV } \\
\text { Atha Mapper 2150 }\end{array}$ \\
\hline $\begin{array}{l}\text { Brushless motor } \\
\text { X4110S 340KV }\end{array}$ & 148 & $\begin{array}{l}\text { Additional of brushless } \\
\text { motor for M } 3 \text { arm } \\
\text { (product specification) }\end{array}$ \\
\hline ESC 40 Ampere & 38.5 & $\begin{array}{l}\text { Additional of ESC } \\
\text { (product specification) }\end{array}$ \\
\hline Servo Motor & 20 & Product specification \\
\hline $\begin{array}{l}\text { Propeller TM1759 } \\
\text { (17 inch) }\end{array}$ & 14.5 & Product specification \\
\hline MTOW & 5490.3 & \\
\hline
\end{tabular}

\subsection{Meshing Size Selection Results}

Based on simulations carried out using variations of meshing ranging in size from $5 \mathrm{~mm}$ to $2 \mathrm{~mm}$, meshing with a size of 2.6 $\mathrm{mm}$ is the meshing that will be used in this study. This is due to the meshing sizes; the percentage of errors that occur is $0.9 \%$ for maximum stress. It can be seen in Table 5 the results of the simulation of the quadcopter spacecraft to be used as the basis for using meshing sizes.

Table 5: Simulation results of quadcopter frames with meshing size variations

\begin{tabular}{ccc}
\hline $\begin{array}{c}\text { Size of } \\
\text { Element }(\mathbf{m m})\end{array}$ & $\begin{array}{c}\text { Maximum Stress } \\
(\mathbf{M P a})\end{array}$ & \% error \\
\hline 5.0 & 56.625 & $17 \%$ \\
\hline 4.0 & 59.010 & $13 \%$ \\
\hline 3.0 & 58.574 & $14 \%$ \\
\hline 2.9 & 62.780 & $8.0 \%$ \\
\hline 2.8 & 63.902 & $6.4 \%$ \\
\hline 2.7 & 64.179 & $6.0 \%$ \\
\hline 2.6 & 67.633 & $0.9 \%$ \\
\hline 2.5 & 66.029 & $3.3 \%$ \\
\hline 2.4 & 66.536 & $2.5 \%$ \\
\hline 2.3 & 72.302 & $5.8 \%$ \\
\hline 2.2 & 70.290 & $2.9 \%$ \\
\hline 2.1 & 71.557 & $4.7 \%$ \\
\hline 2.0 & 71.921 & $5.3 \%$ \\
\hline
\end{tabular}




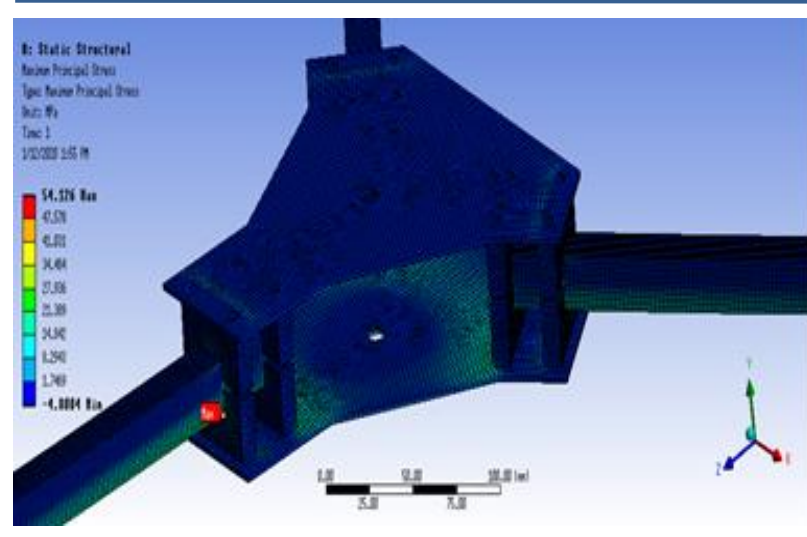

Figure 8: Results of static simulation of a large-scale tricopter frame and maximum stress position

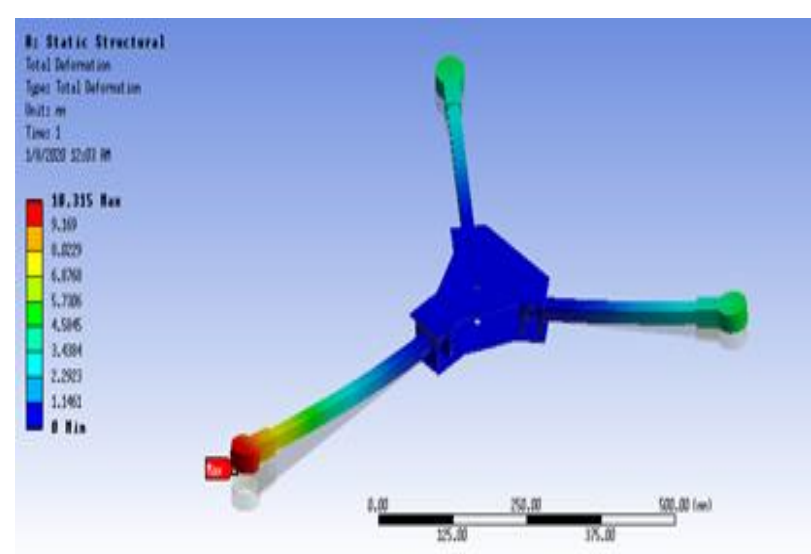

Figure 9: Total deformation that occurs in the tricopter frame

\subsection{Tricopter Frame Static Simulation Results}

Figure 8 shows the simulation results in the form of maximum stress acting on the tricopter arm. In this study, the maximum stress value is obtained using the maximum principal stress theory method. From Figure 8 we can see that the maximum stress occurs in the M3 arm, which is $54,126 \mathrm{MPa}$. This is because the distance between the loading positions to the pedestal on the M3 arm is longer than that of M1 and M2. The maximum voltage point is on the M3 arm that comes in contact with the connecting clamp. This phenomenon is in accordance with the condition of the cantilevered rod that is given loading at the end of the rod, where the greatest stress occurs in the part that is supported.

Deformation is a change in the shape, position and dimensions of a structure due to the force acting. Figure 9 shows the total deformation that occurs in the tricopter frame structure.

In Figure 9, it can be seen that the greatest deformation is at the end of the M3 arm, which is equal to $10,335 \mathrm{~mm}$. Deformation that occurs in the M3 arm is greater than the M1 and M2 arms. This is because the M3 arm longer than the M1 and $\mathrm{M} 2$ arms, so the distance between the loading position and the pedestal getting longer. Deformation of the skeletal structure can affect the performance of the tricopter vehicle because the angle formed on the motorbike can cause instability in the tricopter's motion. Furthermore, for the safety factor value from frame of tricopter design, obtained with a safety value of 8.77 . This shows the value of the safety factor of the tricopter frame structure meets the requirements criteria.

\subsection{CONCLUSION}

The conclusions obtained from the results of this study are as follows:

- A virtual product (design) of the tricopter frame with a Yshaped configuration has been produced, the building material in the form of carbon fiber, acrylic and PLA plastic.

- The tricopter frame structure design has a maximum stress of $54,126 \mathrm{MPa}$, the critical point is on the M3 arm which is clamped using a clamp. Deformation that occurs due to loading from the motor lift force reaches $10,335 \mathrm{~mm}$ at the end of the M3 arm and has a safety factor of 8.77. These results indicate that the tricopter frame with the material making up the combination of carbon fiber, acrylic and polylactid acid (PLA) meets the structural strength requirements.

\section{REFERENCE}

[1] Quan, Q. (2017). Introduction to Multicopter design and control. Singapore: Springer Nature.

[2] Anuar, K., Akbar, M. \& Hersiswanto (2018). Wing design of UAV serindit V-1, IOP Conference Series: Materials Science and Engineering, 539 ((1).

[3] Prayitno, K. (2018). Pembuatan Fuselage, Sayap dan Ekor Pesawat Terbang Tanpa Awak (PTTA). Pekanbaru: Universitas Riau.

[4] Saroinsong, H.S, Poekoel, V.C. \& Manembu (2018). Rancang bangun wahana tanpa awak (fixed wing) berbasis ardupilot. Manado: Universitas Sam Ratulangi.

[5] Astrov, I. \& Pedai, A. (2010). Flight control of a trirotor mini-UAV for enchanced situational awareness. USA: World Academy of Science, Engineering and Technology.

[6] Lukmana, A. (2012). Rancang Bangun Unmanned Aerial Vehicle (UAV) Empat Baling-Baling (QuadrotorArducopter). Surabaya: Intitut Teknologi Sepuluh Nopember.

[7] ASTM D638, Standard Test Method for Tensile Properties of Unreinforced and Reinforced Plastics and Electrical Insulating Materials. ASTM International: West Conshohocken, PA.

[8] Beer, F.P. (2012). Mechanics of Materials. Sixth Edition. New York: The McGraw-Hill Campanies, Inc. 